\title{
Using Chorems in Graphical Modeling: The Case of the Kingdom of Saudi Arabia
}

\section{Mohsen Dhieb}

King Abdulaziz University, Faculty of Arts and Humanities, Department of Geography and GIS, Jeddah, Kingdom of Saudi Arabia Email: Mohsendhieb2003@yahoo.fr

How to cite this paper: Dhieb, M. (2020). Using Chorems in Graphical Modeling: The Case of the Kingdom of Saudi Arabia. Current Urban Studies, 8, 265-283. https://doi.org/10.4236/cus.2020.82015

Received: April 17, 2020

Accepted: June 1, 2020

Published: June 4, 2020

Copyright $\odot 2020$ by author(s) and Scientific Research Publishing Inc. This work is licensed under the Creative Commons Attribution International License (CC BY 4.0).

http://creativecommons.org/licenses/by/4.0/

\begin{abstract}
In geographical research, the use of "chorems" has been presented as a meaningful graphical modeling method of geographical spaces (Brunet, 1980). This method summarizes the specific characters and overall design of one given space whatever its configuration, its extent and its characteristics by using simplified graphical shapes, figures, colors, signs, arrows and textures instead of drawing real maps. The graphical modeling by "chorems" reveals useful to express the profound inner space structures, patterns and relationships of the various areas and different phenomena composing spaces. In this research, one goal is to try to review the set of rules and guidelines to easily realize series of "chorems" that apply to one space. Another goal is to implement, discuss and evaluate a case application of "chorems" on the Kingdom of Saudi Arabia (KSA). The third goal is to measure to what extent this method may be useful to portray and understand spatial inner structures of KSA and how far. Despite some progress and attempts conducted to render automatic the chorems creation or extraction (Laurini \& Serigne, 2001), the author uses the traditional step by step method. The idea behind is to try to discuss each step to make understanding of the whole process easier, especially for Arab readers and Saudi planners. The examples studied are derived from the geography of KSA at the national level. The thematic data are about its main natural and human components and resources, the spatial mobility of its human components and their evolution over time. Compared to the traditional maps used in planning or geographical textbook description of one space, the chorems focus on its main spatial figures and reveal very useful. First, they may help common readers to understand the main characteristics and features of one given space; second, planners and deciders may consider the focal nodes, axes, and areas of one space for featuring its development. Although some limits of the chorematic method, the research findings conclude that "chorems" are figures that may yield useful ideas and guidelines for understanding and featuring the development of one country with
\end{abstract}


regards to its spatial planning policy, i.e., in the case of KSA, to support the future vision of the Kingdom's 2030.

\section{Keywords}

Chorem, Chorematic Method, Spatial Modeling, Saudi Arabia, Spatial Planning

\section{Introduction}

In geographic research, since Christaller (1933) central-place theory and Chorley and Haggett (1967) textbook, many models, methods and means for spatial modeling have been set. The goal is to help geographers, urban planners and other researchers interested in spatial studies to understand, explain and link together the geographical distributions of spatial phenomena, with their components, patterns, shapes and sizes. Among the few methods of great use is spatial modeling, the "chorematic" method, may be considered as an original attempt to synthetize the geographic spaces, whether urban or rural, natural or cultural, to simplify their main structures by using the best basic geometric shapes and signs instead of real configurations (Brunet, 1986, 1987). This may enable common readers to get a general overview about what is the most important when studying one space, and grant professionals the possibility to explain and discuss and even criticize chorematicians' choices. The idea is to describe schematically one geographic space, with its components, powers and obstacles. It may help in the future planning development.

According to the literature, these diagrammatic new graphical schemes and their variants were applied mostly in western countries, especially in France and other Latin countries. But the chorematic method was not sufficiently well known or even applied in Third World countries. For instance, its experiment and application in Arab countries have occurred only rarely (Bord, 1995; Bouattou et al., 2016). Yet, this method proved certain learning qualities and high ability to synthesize space.

The structure plan of the research gives first a brief review of the used terms and an overview of the literature review related to chorems and the chorematic method. Second, the author tries to look for and implement the best geometric shape that fits KSA external outlines. Third, departing from the geographic literature (Dhieb, 1994), the research aims to consider and identify the existing potentialities of the country, its main infrastructure nodes and axes and its main areal land components. These latter include cities, villages and deserts, energy poles, industrial plants, touristic and archaeological sites; the major axes that connect them; and the areas constituting the substratum of KSA. The final step focuses on the benefits and the limits of using such a method, as well as recommendations for future projects to maximize profits and usefulness. By doing so, the chorematic method may support decision making. 
The case study is the Kingdom of Saudi Arabia (KSA). Economically, it is the second economic power in the Middle East (after Turkey), and geographically, the second country in the Arab world (after Algeria). It is characterized by the diversity of its landscapes and the disparity of its components, (natural and human), and the richness of its resources. Saudi Arabia has also a huge potential and heritage to grow, develop and take advantage of its capabilities. For these reasons, choosing the chorematic method to simplify and summarize a very complex constitutes an additive value. It may help common readers to have an overview about this influencing country on the international scene and Saudi politicians to think about a comprehensive vision modern enough to develop KSA territory within a coherent integrated plan for the next decade: the Saudi Vision 2030.

\section{Terminology and Literature Review}

Explanation of the basic terms related to the fields of "chorem" and "chorematics", and clarification of the conditions of implementation of this graphical modeling method, require thorough understanding and knowledge of the territory to design it in an understandable manner.

"Chorematics" ("Chorématique" in French and "Chorematics" in English) means a geospatial-cartographic modeling method that simulates geospatial space by creating simplified graphical geometric shapes and drawings. It aims to create one or several models that show the use of chorems with simplified graphic figures the most important elements of one geographic space, its components and salient characters. For that, Brunet defined what he called "the alphabet of space" (Brunet, 1980). He warned that chorematism is not limited to simulation, and its results are not guaranteed in advance. Indeed, chorematism does not imply a simple skill to represent space, but it requires a wide knowledge to diagnose and clarify the hidden or unknown space structures of the geographical space, its conceals, patterns and forms, whatever the space is and whatever the spatial structures are, by pointing their strengths and weaknesses.

The terms "Chorem", coreme (Martinuci, 2016), choreme or even the French term "Choreme", if we refer to Laurini et al. (2009), are derived from the Latin word (Choros) which means the region, space, or range. Every product of the "chorematic" method is called "Chorem" as the elementary representation of the space structure, whether in form of points, lines, areas, meshes, or any similar shapes or combinations of such elements.

Sometimes the term "Chorem-map" (In French Carte-choreme) is found as an expression of what is applied to geographical maps using the method, regardless of the space and field of representation. It runs through the whole world to the smallest territory, including all the intermediate geographical scales. It is also sensed pointing out the main natural and human geographic issues, whatever the field study, the scale of the data, its quality, its extension and its various characteristics. 
Two other terms are added by the researcher to this chorematic lexicon to express two other concepts to distinguish between them in the field of chorematism: implantation (implantation in French) and imposition (imposition in French).

The first term is the concept of "Implantation" which is borrowed from the French cartographer Bertin, in which there is the root of plan, i.e. the surface (Bertin, 1967, 2005; Dhieb, 2019). It deals with the three forms in which the symbols and signs on the map may be an expression of geographical phenomena of the geographical field: punctual implantation representing for instance the cities of the Kingdom; linear implantation such as roads or valleys in the Kingdom; and areal implantation when it comes to whole areas of geographical space, such as administrative areas, or terrain entities, climatic or vegetative units of the Kingdom.

The second term is "Imposition" from the French term "Imposition", which was also created by the famous French cartographer Jacques Bertin. It means the type or kind of "graphic" representation, that every geographical phenomenon takes, in the case of graphical representation: diagrams, networks (graphical), map or symbolics products (Bertin, 1967, 2005).

But when applied to chorematics, these two concepts have a greater number of components as revealed by what the author considers probably as the most important tools created by R. Brunet: the "Chorem table" (Tableau des chorèmes). Brunet published a first article entitled: "The Composition of Models in Spatial Analysis" (Brunet, 1980 in "Geospatial", $4^{\text {th }}$ issue) explaining the chorematic method. Then, he published other articles and a textbook in which he laid out an integrated plan for the method of chorematics modeling in the form of a table containing 4 forms of implantation of geographical phenomena (point, line, area and network), and 7 possible cases of imposition. These 7 characteristics are namely (texture, square, attraction, contact, position, dynamic and spatial arrangement) in Laurini et al. translation (Brunet, 1987). The total of possibilities of forms or types of chorems components were initially 28 , but some others added dimensions or, and characteristics (https://cs.wordpress.org/). One of the translated versions of this table is presented in Figure 1 by VanElzaker, in 2004, cited by (Reimer, 2010).

The roots of method date to the seventies, but it was developed in the eighties of the last century, thanks to the French geographer Roger Brunet (1972, 1980, $1986,1987)$. He is considered as the founder of the chorematic concept and the chorem term (choreme in French and chorem in English from the formal Greek choré and the suffix ème). Gradually, it was adopted and developed by other geographers and cartographers (Arreghini, 1995; Brunet, 2001a, 2001b; Rodier et al., 2015). The method was presented in textbooks (Brunet, 1987) and widely used to study various geographical fields such as agriculture (Brunet, 1980; Cheylan et al., 1990) or territorial development (Brunet, 2005). It was also used in spatial analysis and database extraction (Del Fatto et 


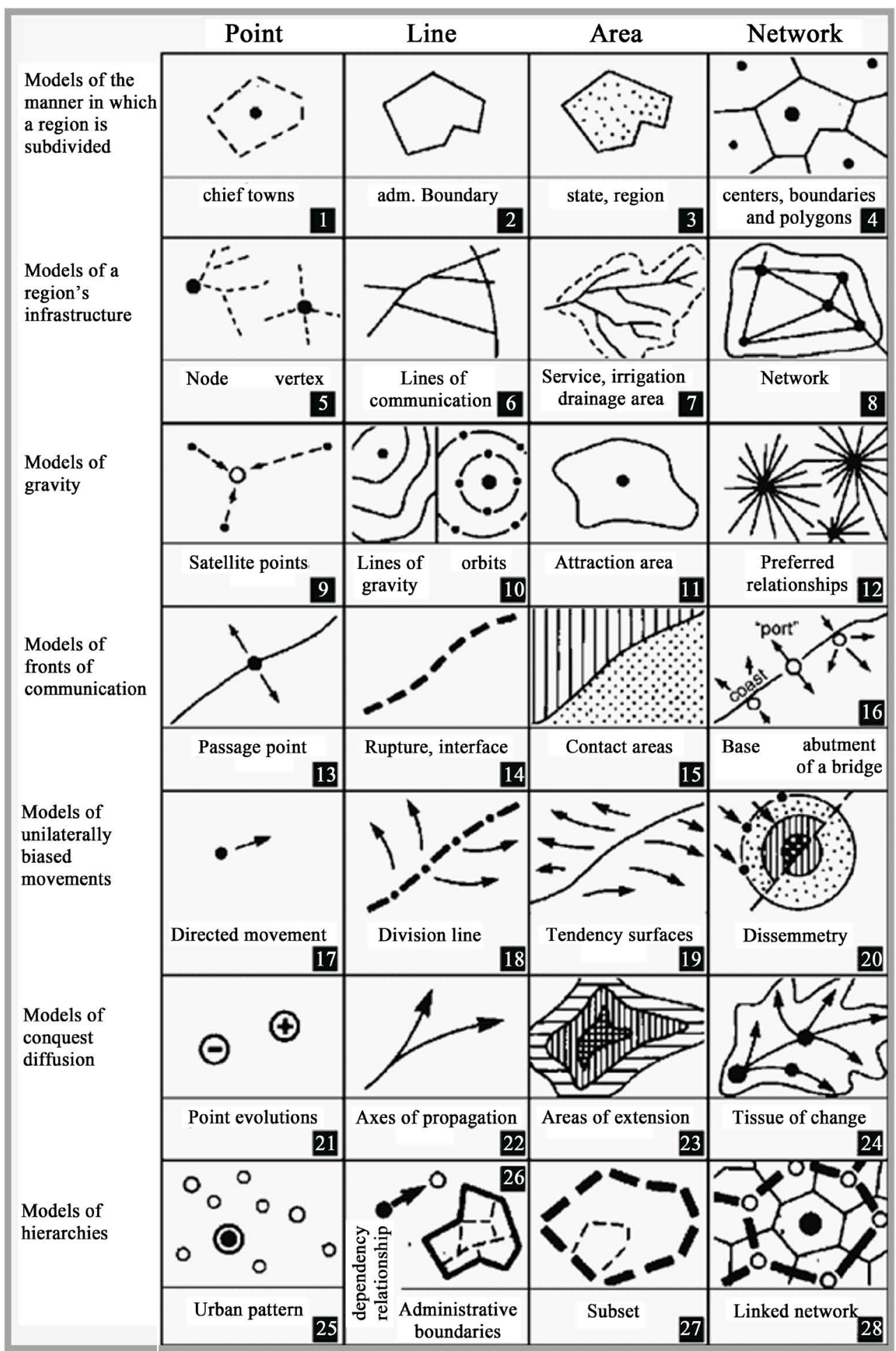

Figure 1. The table of chorems (Brunet, 1986), cited by (Reimer, 2010).

al., 2007a, 2007b, 2008; Coimbra, 2008), or mapping representation as in the atlases (Théry, 1986; Ferras, 1986). A few academic research works were conducted in academic milieu (Lowy, 1985; Del Fatto, 2009; Lopez-Guillen, 2010). Some cartographers conducted researches for developing the method to chro- 
no-chorems (Rodier et al., 2005), automating the method and extracting the basic forms of space whether punctual, linear or areal from databases (Laurini and Serigne, 2001; Coimbra, 2008; Laurini et al., 2009). Recently, some attempts were conducted to give the production procedure of "chorems" an objective or a systematic character (Del Fatto, 2009; Cherni et al., 2010).

\section{The Chorematic Methodology}

The research methodology is mainly based on the rules, principles and recommendations formulated by Roger Brunet (1980) and his table; later, some authors developed multiple chorematic studies (Rodier et al., 2015; Martinuci, 2016); books were written (Brunet, 1987; Durand et al., 1992). Academic research and scientific articles and attempt of automation (Laurini and Serigne, 2001) and programming (Coimbra, 2008) were conducted. It should not be forgotten that many applications were realized on chorems applications; some of them were included in research articles where others were used thoroughly in dedicated books and atlases (Théry, 1986). The significance of the chorems is derived from the extent of their conformity to the studied case, when tested and compared to reality (Klippel et al., 2005).

It is worth noting that, the criticism addressed to the chorematic method in modeling geographical space, considers that the method is not based on an objective, non-debatable scientific methodology (Collectif, 1995). Chorematics depends on the ability of the user to read the space and infer the hidden elements that make up its structure and skill. This will be done in converting the entire map components into an authoritative drawing that may help to understand the way the space works and the interconnectivity of these components. So, it may help to view how it will be planned to improve and develop spaces. Indeed, according to the literature, many unusual applications such as chorems have proven their ability to simulate geographic spaces in a smoother and seamless graphical way, when compared to some complex and slightly readable traditional maps.

The graphical modeling of geographical space, using the chorematic method, means first looking for a basic shape that represents its basic structure by focusing on the outlines of the overall form of this space, leaving what is considered as secondary or superfluous and distracting the user's mind. This is done after a careful and thorough study of its geographical features-whatever their size and shape-their components, their most important characteristics, and their strengths and weaknesses. It is a repetitive, inductive, and deductive pendulum process, which progresses to approaching the overall shape, by its simplification, sketching, modification and revising until it reaches a satisfactory form. It is a process that depends on the extent of the researcher's knowledge of space and his ability to see a compiled synthesis and a careful reading of it, to point out its developmental and progressing areas.

Departing from all these assumptions and statements and considering the re- 
sults of previous studies and applications, the author has tried the method on KSA for the first time, as far as he knows. The following paragraphs supported by corresponding figures of the whole process of chorems implementation summarize the following steps that the researcher has taken up to reaching a geographical form of the Kingdom based on the chorem-map method.

\section{Searching the Basic Best Shape}

The chorematic process implies the selection of an external geometrical shape that would suggest the better and original form of the studied territory. The issue is to be able to control it more easily and facilitate its preservation and consolidation in memory, to be able to represent the initial spatial assumptions in the initial plan. The borders of the Kingdom were first drawn; the sea offshore and other international borders of the neighboring countries were not, since the goal was limited to setting up a facilitated structure for internal spatial planning considering the strategic vision 2030. The design of the first drawing was generalized to bring it closer to geometric figures (Figure 2).

Looking closely at the shape of the outer Kingdom, one may notice that the closest similar geometric shape could be a trapezoid. But the disadvantage of such shape is that it is irregular, and therefore more difficult to use than other regular geometric forms. So, the author should find out a closer geometric form even though its borders or perimeter may be slightly different from the real ones, but it is certainly easier to use in the following steps and in graphic modeling in general. According to Lee and Sally's rule (Clarke, 1990), in trying to approximate irregular shapes from the circle, a circle equivalent to the area of the Kingdom was drawn and placed over the original map, in its center precisely. The result is that we have equivalent areas outside and inside the circle (Figure 3).

Obviously, the northwestern-southeastern length of the Kingdom requires that the circle should be stretched to fit a real ellipse. Going back to the original base map, the author notices that the angular shape is closer to the rectangle than the elliptical shape and the like (Figure 4).

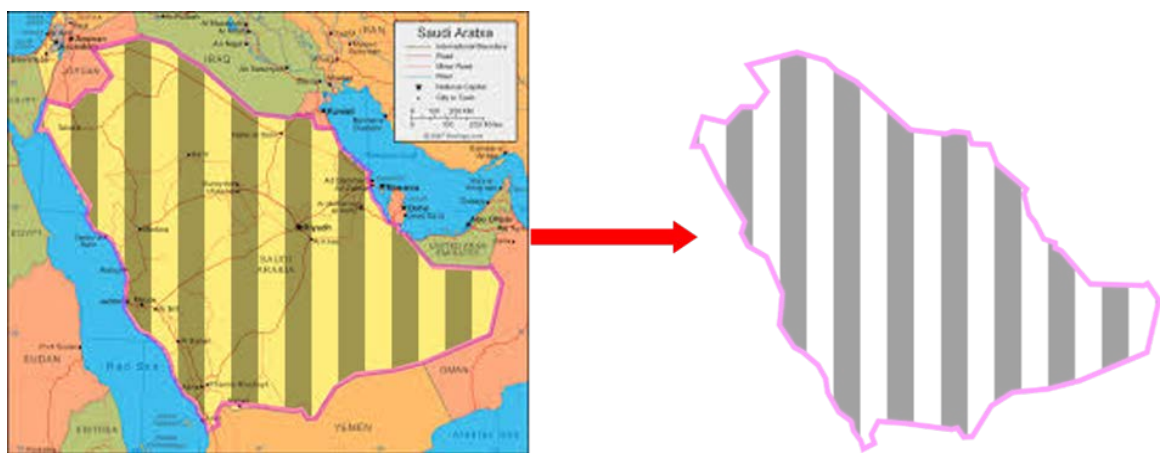

Figure 2. The true form of the Kingdom of Saudi Arabia map extracted from the base map with a suitable line generalization degree for small scale. Note that the author did not include the borders of neighboring countries, because the study is only concerned with the development plan for the Kingdom within the Vision 2030. 
Therefore, the author drew on oblique rectangular shape over the ellipse, approximately oriented from the north-west to the south-east. Finally, the author retained the oblique form of the rectangle (Figure 5).

To make the rectangle simpler, Figure 6 shows that the final rectangle

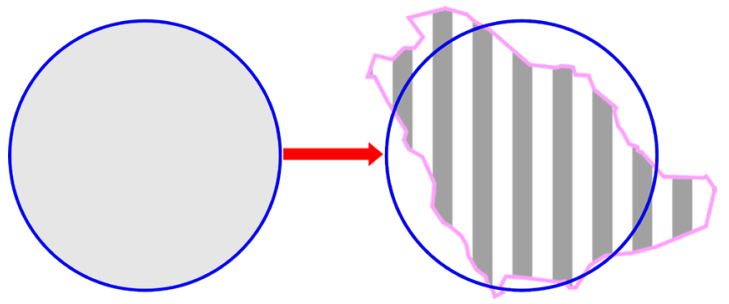

Figure 3. From the map to the most "neutral" geometric figure: the circle. The author puts a circle equivalent to the area of the Kingdom, then transferred it based on the Kingdom's territory, covering most of its parts and equating its extra parts. In the circle, the area is not covered by the Kingdom and is symmetrical in all directions.

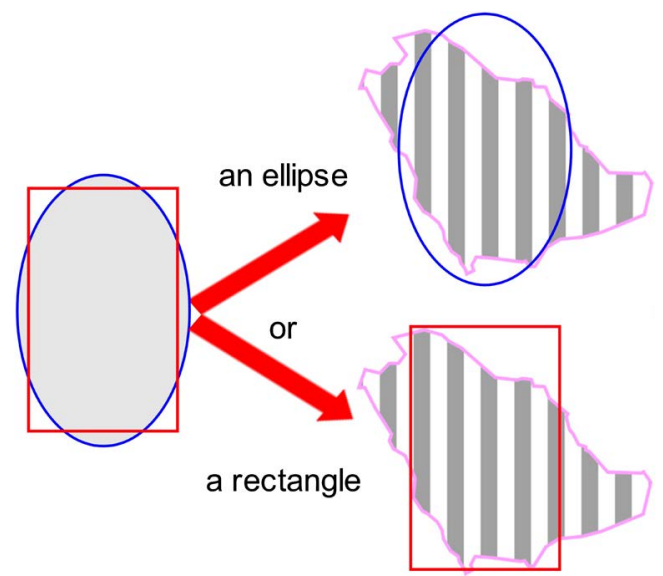

Figure 4. The general shape of the Kingdom is closer to an elliptical or a rectangular form than the circle. So, first the circle was transformed to an equivalent ellipse, with equivalent area, then an equivalent rectangle was drawn over it. Either way, one is quite sure that the area with the original base map was equal.

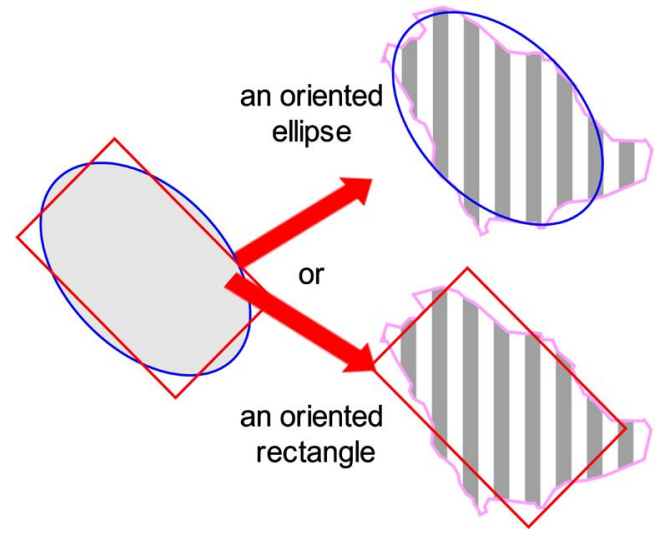

Figure 5. The author noticed that the orientation of the two shapes requires to rotating them by about 45 degrees clockwise; therefore, the general direction of the shape fits the longitudinal shape of the Kingdom oriented Northwest-Southeast. 


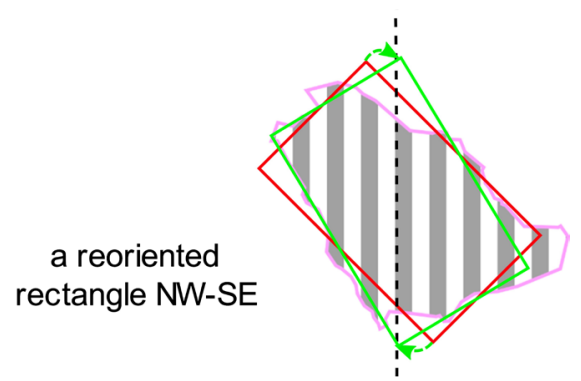

Figure 6. Decision to choose the rectangle as the basis for the chorem-map of KSA was made, after its slight rotation to fit the northwest-southeast right clockwise, as shown by the vertical straight line. This is due to the regularity of this shape and what may be facilitated by its simplified angular geometric shape. This is to facilitate the geographical and thematic design of components in the next steps.

adopted as the basis of the chorem-map of the Kingdom of Saudi Arabia. According to the "chorematic" rules and principles, the rectangle observed a slight additional rotation at a slight angle was operated. The final rectangle has a diagonal corresponding to the vertical line always for the purpose of simplicity and to give it a complete and regular geometrical character (Figure 6).

After creating the chorem-map skeleton for the Kingdom, it is necessary to implement the basic salient data that may synthetize this country. The reader must be warned that the vocabulary of implantation, i.e. phenomena and symptoms that represent prominent points in the geography of the Kingdom, are positioned gradually, as the cartographic methodology requires, from points, then lines, then areas, and finally the relations between them. The final chorem-map highlights these steps.

It is worth noting that the chorematic method can be downloaded into several geographical levels or observed over time as demonstrated by Rodier et al. (2015), according to the target and the available data. Moreover, chorematic modeling allows the transition between the national level to the regional levels and even the local levels. In this paper, the author has chosen the threshold of the national level that corresponds to the KSA Vision 2030 and the resulting national planning, while other levels can be appropriate for regional planning and download options at urban, village or rural levels.

\section{The Basic KSA Inner Structures}

\subsection{The Major Saudi Poles}

In an overall synthesis of the Kingdom's space, the most important polarization points or the "nodes" are represented by the major cities. The criteria are not only in terms of population numbers or areas, neither because of the high percentage of urbanization in the Kingdom which exceeds 83 percent, but because of their administrative position and the major roles they perform at the international, national or regional level in the fields of industry, services and tourism (https://www.citypopulation.de/en/saudiarabia/). For this, the author has chosen 
the following cities: the capital Riyadh and Jeddah at the highest international level (the biggest poles); Dammam, AlTaif as well as Mecca and Medina as two religious' poles at the first national level. Other main cities should be drawn progressively depending on the studied theme at tertiary level.

All of the major five poles are centered on a northeast-southwestern line that mediates the Saudi space, which confirms the dominance of the polarized areas over the greater part of the Saudi territorial space and the need to take into account the polarization of their countryside whether rural, desertic, or by modified interpolations (Figure 7).

The cities put at a tertiary level are the cities of Tabuk in the north, Abha coupled with Khamis Mushayt in the south, Al-Baha, Hail, Jizan, Al-Qassim, Khobar and $\mathrm{Al} \mathrm{Hafouf} \mathrm{(Figure} \mathrm{8).}$

It is also possible to add to the industrial poles of as the most important industrial oil cities in a third level.

In addition to the cities, it must also be pointed out that some other stations are poles in the Saudi geographical space: religious cities that have a distinguished position in the Islamic world, industrial cities of Jubail in the east, Yanbu and Rabigh in the west, the port of Jeddah the major airports (Figure 9).

\subsection{Linking the Poles: The Role of Major Axes}

The axes are formed according to the connections between the Kingdom major and great cities, but some of them may be caused by natural factors such mountainous barriers, or relational factors imposed by intense transactions and exchanges

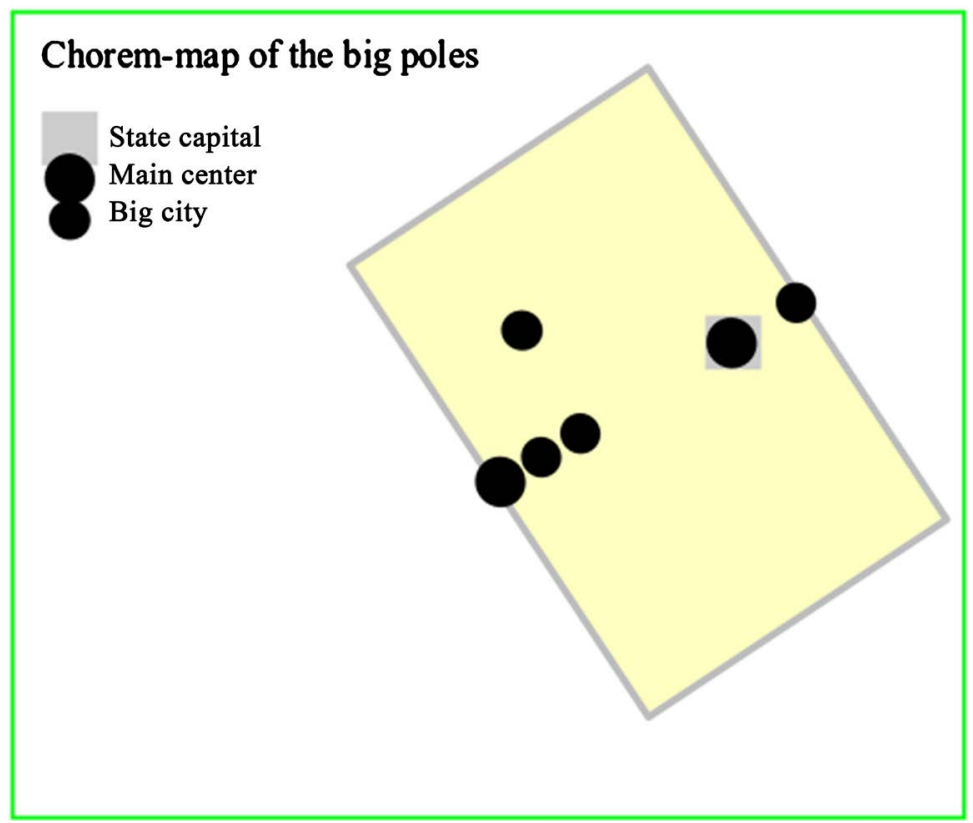

Figure 7. The most important urban poles in the Kingdom have been implemented on the chorem-map. The author tried to put cities on axes to prepare the next step dealing with the roads and flow network. This geometric way of design is recommended to make or continued connection. 


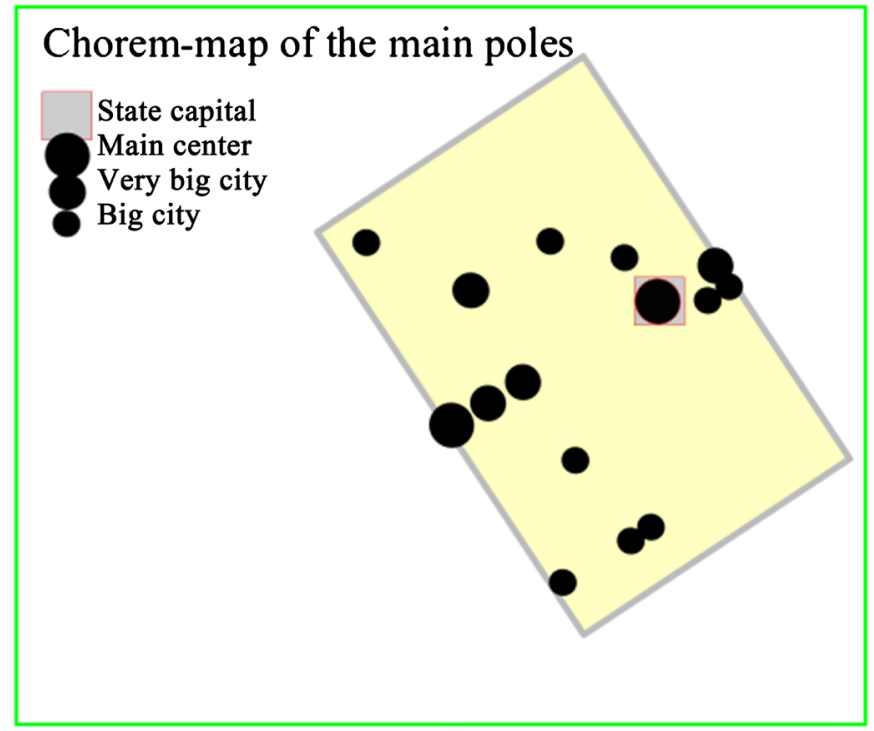

Figure 8. Besides the most important urban poles in the Kingdom that are the middle axis, there are other cities which may form other axes; the most important are the western coastal axis, the mountainous axis and the northern axis from Tabuk to Dammam.

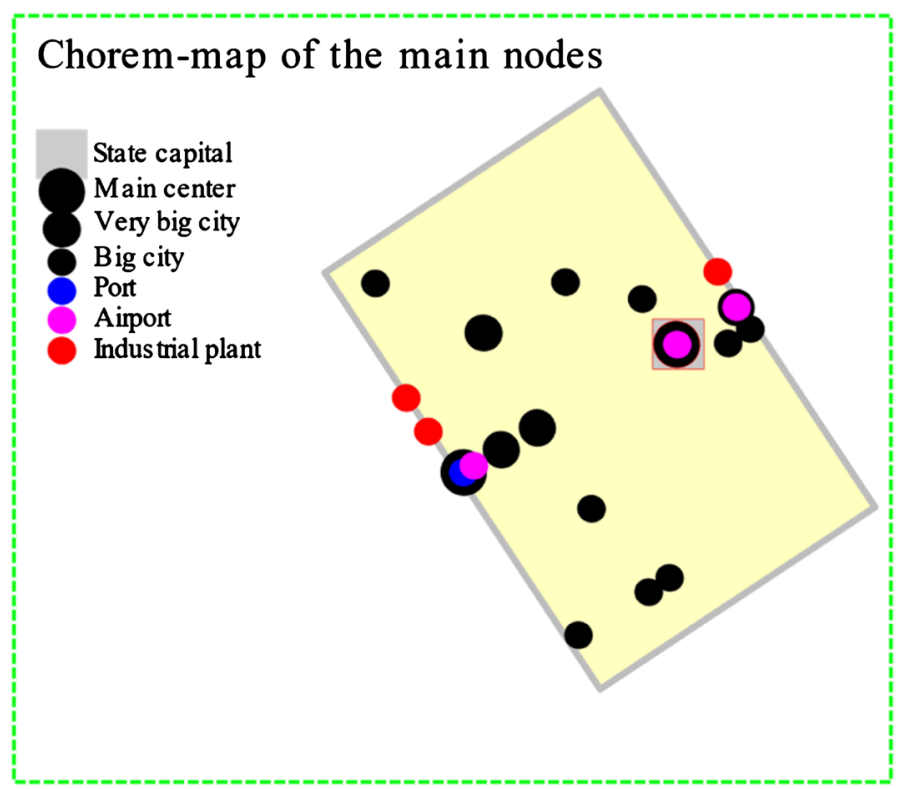

Figure 9. The most important urban poles in the Kingdom form the main axes of the territory: besides the middle and the western axes, there are other axes; the most important are the western coastal axis, and the northern axis from Tabuk to Dammam.

between regions for various reasons: human, economic, religious or touristic. Considering the available human and economic data, we obtained a few main axes, mainly diagnosed by roads and exchange paths for people and goods and the density of air transport lines. They correspond roughly to the location of the major cities and poles selected as spatial nodes. The author manages also, as far as possible, to put the axes within or on the edge of the major topographical units of the Kingdom, which are mainly based on major terrain units such as 
Asir and Hijaz Mountains, the Arabian region, the coastal plains and the important deserts. When adding the axes to the nodes, we obtained (Figure 10).

The author also made sure that the drawing was made in a geometric way for the land and sea borders, which sometimes represents opportunities for exchange and sometimes barriers for geo-strategic reasons, including the internal axes of internal exchanges first, and at a second stage, to describe these axes with colors and distinctive symbols to indicate the different roles they play as elements facilitating or disabling natural or human exchanges and relations.

It is worth noting that the author did not touch on the issue of inner natural barriers or limits such as mountains or borders between tribal areas or relational as some international borders for political or geostrategic reasons. These borders do not fit in our research goal that deals with the internal situation of the Kinfdom and its planning according to the Strategic Vision 2030 (Figure 11).

\subsection{The Horizontal Substract Weft: Not Only a Desert!}

To complete the main Saudi structures, it is worth noting that the largest part of the area of the Kingdom is made up of vast terrain or desert units called Ar Raf Al Arabi as shown in the space image of the Kingdom, but also central hills called Ad Diraa Al Arabi, coastal narrow plains, western mountainous chains (Figure 12).

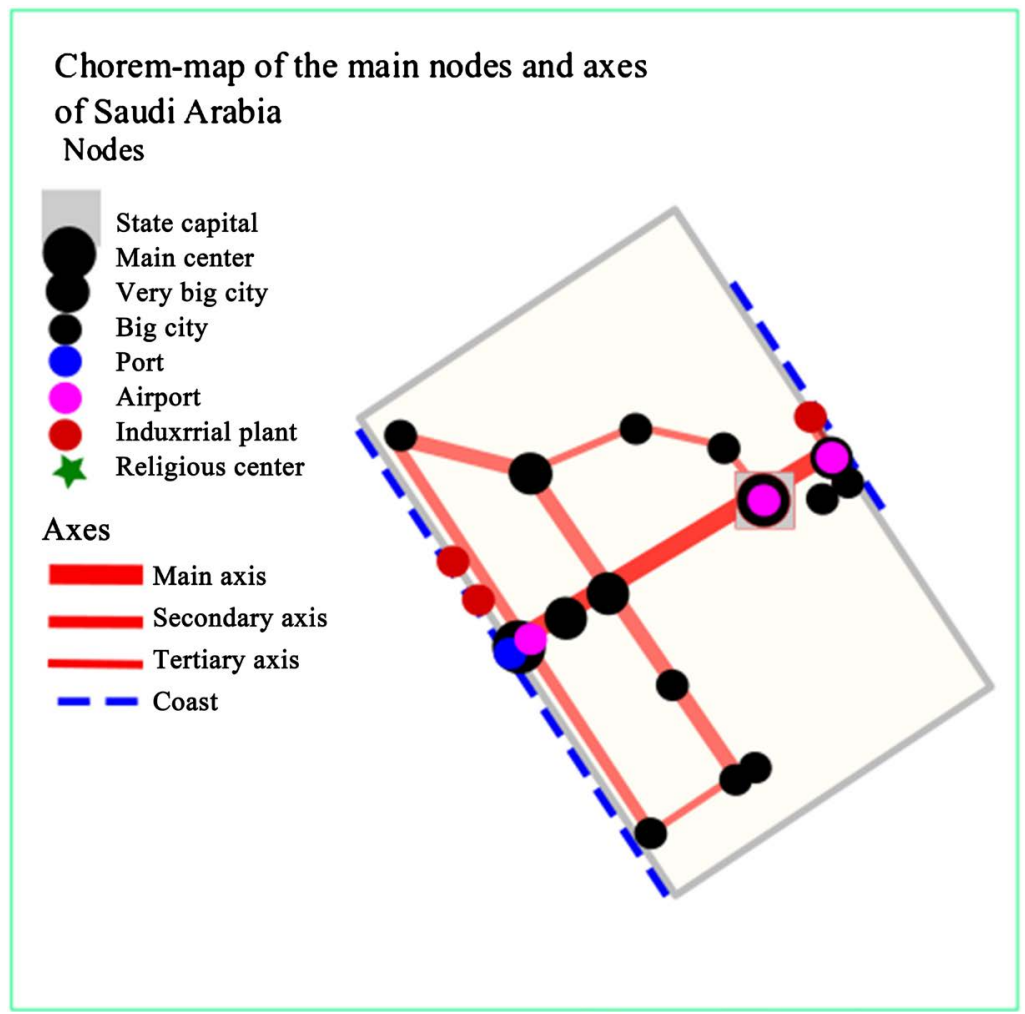

Figure 10. In addition to the most important urban poles in the Kingdom that formed a central cross axis, other axes were formed. The most important of which are the mountainous western axis, doubled by a coastal axis of great importance in the future. 


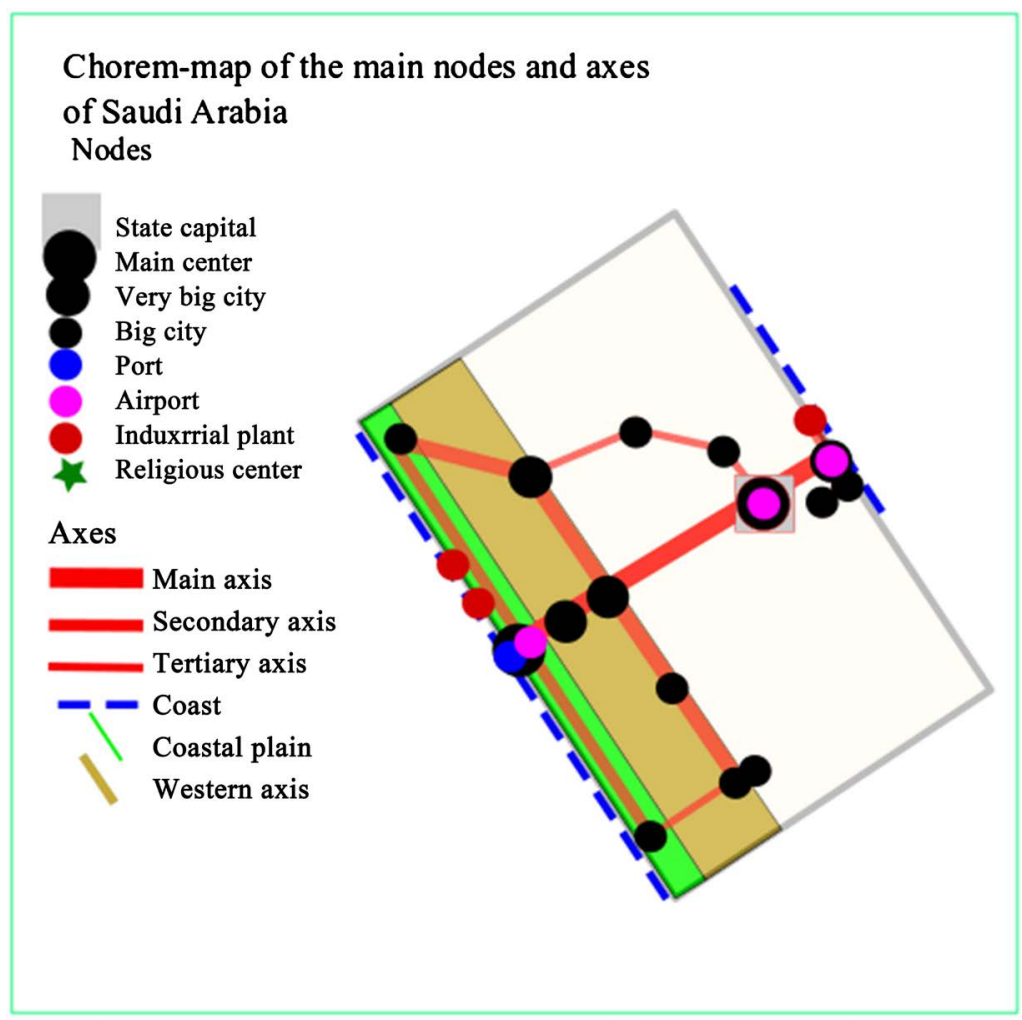

Figure 11. Figure 11 shows another view of additional axes: the most important are the western green coastal plain and the chain of mountains of Al Hijaz-Asir represented in brown, which may be considered as ribbons rather areas.

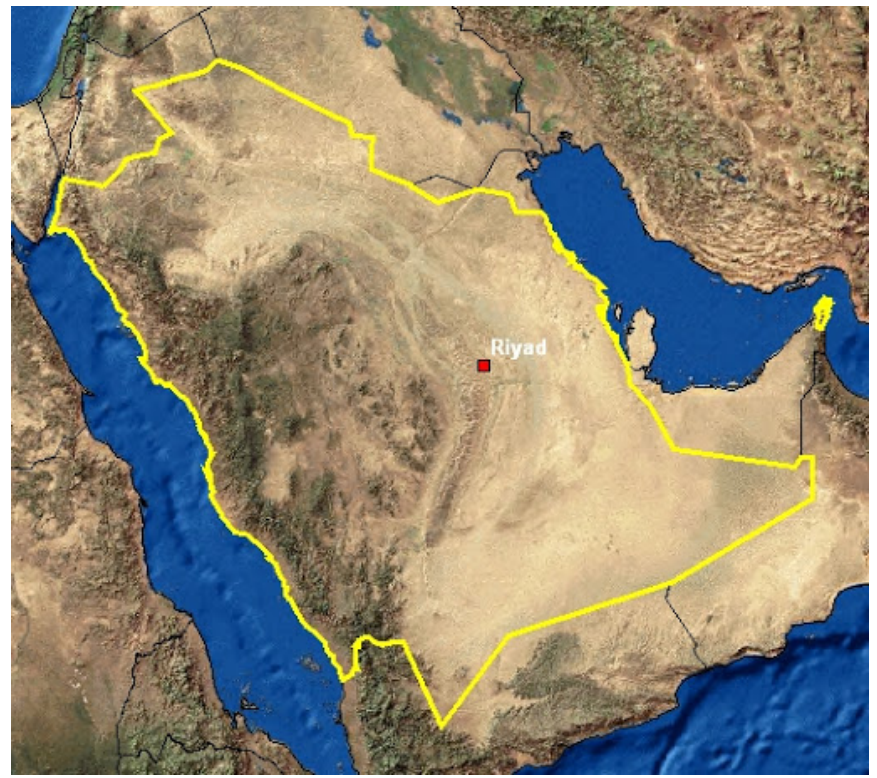

Figure 12. The most important Saudi geographical regions that are mostly made up of deserts, especially in the eastern and southeastern part (Ar Raba Al Khali, literally "the Empty Quarter") and mountains, both in the form of chains mountains (Hijaz and Asir) or within the Arab Shield in the form of plateau or mountains not elevated. There is also a narrow western coastal plain, but it is extremely important economically. The author has added to the map some axes adjacent to this area. 
This does not mean that these areas are useless in relation to the Kingdom's 2030 vision. Rather, on the contrary, these vast areas represent first strategic reserves for agricultural or non-oasis extension, whether cultural (fruits, vegetables, and cereals) or for breeding (cattle, sheep, goat, camel and chicken). Second, the western and central areas great reserves metallic and non-metallic minerals that may support the growing expansion of the manufacturing industrial expansion. Third, the eastern areas of Saudi Arabia contain the most important oil and gas fields in the world and Saudi Arabia plays a central role in the oil world market. Fourth, one can imagine an increasing exploitation of touristic sites, tourist routes and hiking potentials (Figure 13).

The Saudi substratum may play a central role besides resources provided by pilgrimage and oil and gas industry if investments and settlement of population are achieved. Moreover, this role is progressing over time and one cannot ignore this fact. These elements would be studied rather at lower study levels (Figure 14).

\section{Conclusion and Prospects for Developing the Chorematic Method}

The research on the Kingdom of Saudi Arabia shows the importance of using

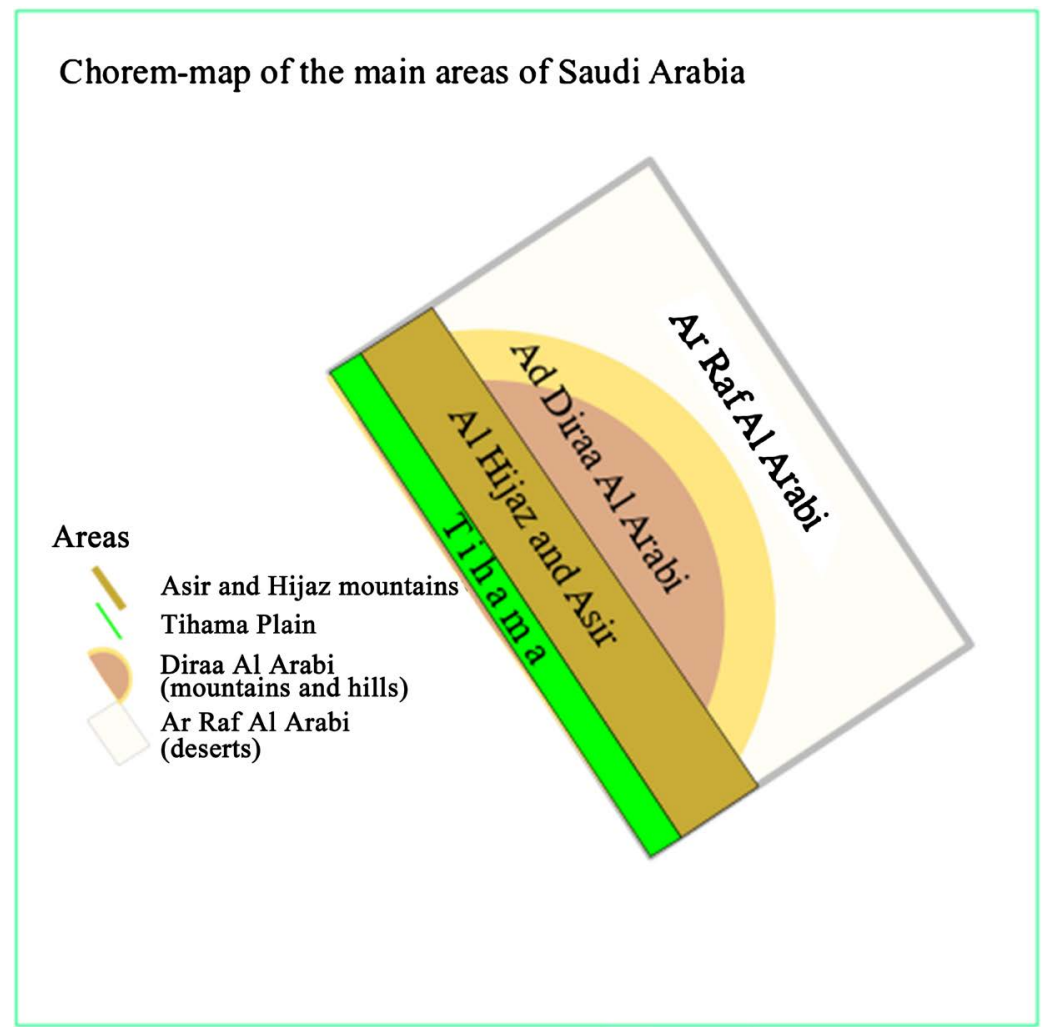

Figure 13. The most important Saudi geographical regions are "choremized" in this chorem-map. It illustrates the main horizontal structures of the Kingdom: wide deserts, especially in the eastern and southeastern parts; mountains (Hijaz and Asir) or within the Arab Shield in the form of plateau or mountains not elevated; and narrow western fertile coastal plain opposed to the wider eastern plain mingled with the desert. 


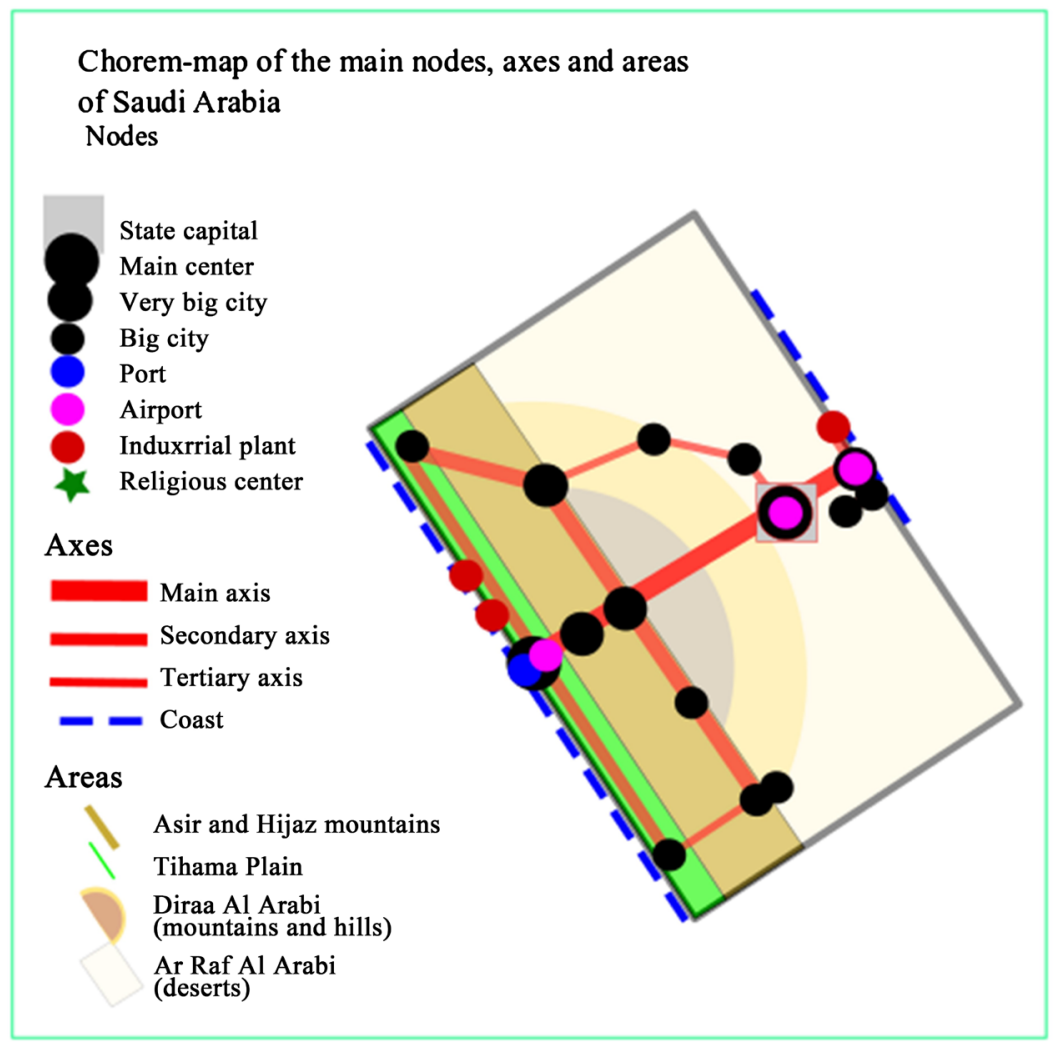

Figure 14. The final chorem-map of the Kingdom, which rounds off the bulk of the chorem that was created for poles, axes, and areas after making some partial adjustments.

graphic spatial modeling with the use of chorematic method in geographical research. The traditional map gives an accurate picture of the geographical reality, but it does not point out clearly the spatial inner structures on which this spatial components and correlations are based. The study showed the vastness and importance of the areas that appear to be unused until today and can represent a strategic reserve for the Kingdom to use in the future development Vision 2030.

The chorematic method is important in spatial planning because it summarizes the inner structures relatively easily. Then the matter is more difficult when it comes to content because it assumes that important elements are not left out. The question of importance and appreciation of what is important and what is less important remains a matter worthy of study and for which measurable controls and standards are established. The experimental study showed that the search for the best shape led to the selection of the oblique rectangle 45 degrees to the left. The ultimate chorem-map gives a clear idea of the actual composition of Saudi space and its overall composition in a simplified and synthetic form.

Many authors conducted researches which demonstrated the importance of automating the extraction of critical data from databases to integrate into the design of the chorem (Laurini \& Serigne, 2001; De Chiara et al., 2009) as an attempt to develop chorem and extract it from its own limitations. But in the future, cartographers are encouraged to develop the process of searching simpler 
forms of geographical spaces based on chorems diagrams; further research on automation can enhance this procedure. The chorematic research procedures should be developed and given a more objective character.

However, chorems should consider critics addressed such as the ones related to the exaggeration of simplification of geographical areas and their implementation procedures. Future researches should also minimize as far as possible the subjectivity of chorems in diagnosing the strengths and weaknesses of these geographical areas, and in retaining what is more important to consider as main structures (De Maximy, 1987). Techniques such as data mining can help. This study achieved on the national level of KSA should be a trigger for future studies on regional, urban, or sectorial levels.

\section{Recommendations}

By using the chorematic method, the research on the graphic modeling of the Kingdom of Saudi Arabia revealed schematically the inner spatial structures of the Kingdom. But further research on the issue dealing with thematic and/or regional chorems of the country should be conducted.

Many recommendations can be suggested:

1) The importance to use graphical modeling in geographical research. This may help professionals and common users to get general and schematic idea about unknown spaces.

2) The necessity to sufficiently review references and data on the studied spaces before designing chorems (De Maximy, 1987). Chorems' implementation should start with compiling and designing the scientific material with the data forming the creation of chorems, including exploring the components of what should be the hidden structures of the studied geographical space.

3) Experimentation and consideration of the users' view on the produced chorems and after comparing them with the original maps to enhance them. Revision and amendment to reach the best results are recommended.

4) The design of chorematic models gradually, according to controlled steps and arranged with regards to the relevant literature on the figures and patterns that fit the best the studied spaces.

5) The choice of the best overall simplified basic shape, and if possible, a regular geometric one, determines in a great part the success of the future arrangement of the other main figures composed of poles, axes and areas to show the relationship between them.

6) The necessity of choosing appropriate symbols and colors for the designed phenomena and obeying the semiological rules.

7) The relationships between poles, axes and areas should be designed gradually but all steps are interrelated.

8) Do not consider axes as positive factors in exchange, movement and development. They can also represent barriers or obstacles for them, for natural, human, historical or political reasons. 
9) In future research on chorems, it is worth enriching the final map by adding the external actors and events happening in the future planning of the studied space. It applies to KSA where at least two factors may have a great influence on the international political and geostrategic scene: oil and pilgrimage.

10) Consider the developmental decisions that may be integrated in the process of development: we may cite here huge projects and investments such as the enhancement of touristic sites such as Madain Saleh, some natural reserves, and some huge infrastructure facilities such as the Haramain train or the future city of Nayoum planned (Saudi vision 2030).

\section{Acknowledgements}

This project was funded by the Deanship of Scientific Research (DSR) at King Abdulaziz University, Jeddah, under grant No. G-1569-125-1440. The author, Pr. Dr. Mohsen DHIEB, therefore, acknowledges with thanks DSR for technical and financial support.

\section{Conflicts of Interest}

The author declares no conflicts of interest regarding the publication of this paper.

\section{References}

Arreghini, L. (1995). La modélisation graphique dans la réalisation des atlas pour le développement. Journées Géographiques de l'ORSTOM, 11-12/09/1995, Maison de la Géographie, Montpellier.

Bertin, J. (1967). Sémiologie graphique. Paris: Mouton/Gauthier-Villars.

Bertin, J. (2005). Sémiologie graphique. Paris: Editions EHESS.

Bord, J.-P. (1995). Modélisation du Monde Arabe. Revue Mappemonde, 2/1995. https://www.mgm.fr/PUB/Mappemonde/M295/ARABI.pdf

Bouattou, Z., Laurini, R., \& Belbachir, H. (2016). La génération des résumés visuels de flux de données de capteurs météorologiques avec des chorèmes. In $E G C$, Volume E-30 of Revue des Nouvelles Technologies de l'Information (pp. 527-528). Éditions RNTI.

Brunet, R. (1972). Organisation de l'espace et cartographie de modèles: Les villes du Massif Central. L'Espace Géographique, No. 1, 43-48.

https://doi.org/10.3406/spgeo.1972.1298

Brunet, R. (1980). La composition des modèles dans l'analyse spatiale. L'Espace géographique, No. 4, 253-265. https://doi.org/10.3406/spgeo.1980.3572

Brunet, R. (1986). La carte-modèle et les chorèmes. Mappemonde, No. 4, 2-6.

Brunet, R. (1987). La carte, mode d'emploi. Paris: Fayard-Reclus.

Brunet, R. (2001a). Le Déchiffrement Du Monde. Théorie et Pratique de la Géographie, Paris: Belin.

Brunet, R. (2001b). Models in Geography? A Sense to Research. In 12th European Colloquium on Quantitative and Theoretical Geography (Article 204). St-Valery-en-Caux. https://doi.org/10.4000/cybergeo.23972

Brunet, R. (2005). Le développement des Territoires: Formes, Lois, Aménagement. La 
Tour d'Aiges: Editions de l'Aube.

Cherni, I., Lopez, K., Laurini, R., \& Faiz, S. (2010). Un langage et un générateur pour représenter les résumés visuels de bases de données géographiques. In 7ème Atelier Fouille de Données Complexes dans un processus d'extraction de connaissances. Complexité liée aux données multiples (pp. 103-114). https://www.researchgate.net/publication/229022233

Cheylan, J., Deffontaines, J., Lardon, S., \& Théry, H. (1990). Les chorèmes: Un outil pour l'étude de l'activité agricole dans l'espace rural. Mappemonde, No. 4, 2-4.

Chorley, R. J., \& Haggett, P. (1967). Models in Geography. Methuen: Londres.

Christaller, W. (1933). Die zentralen Orte in Süddeutschland. Iéna: Université d'Iéna.

Clarke, K. (1990). Analytical and Computer Cartography (2nd ed., 350 p.). Upper Saddle River, NJ: Prentice Hall.

Coimbra, R. A. (2008). ChorML: XML Extension for Modeling Visual Summaries of Geographic Databases Based on "Chorems”. Thèse en Master, INSA de Lyon.

Collectif (dir of Lacoste, Y.) (1995). Les géographes, la science et l'illusion. Hérodote, No. 76.

De Chiara, D., Del Fatto, V., Laurini, R., Sebillo, M., \& Vitiello, G. (2009). Visual Analysis of Spatial Data through Maps of "Chorems”“. In S. K. Chang, A. Celentano, \& A. Yoshitaka (Eds.), Proceedings of the 15th International Conference on Distributed Multimedia Systems (pp. 295-300). Skokie, IL: Knowledge Systems Institute.

De Maximy, R. (1987). Chorème et chorématique, La cartographie en débat (pp. 119-128). Représenter ou convaincre.

Del Fatto, V. (2009). Visual Summaries of Geographic Databases by "Chorems". Thèse de Doctorat, En Cotutelle INSA de Lyon et Università di Salerno (Italie).

Del Fatto, V., Laurini, R., Lopez, K., Loreto, R., Milleret-Raffort, F., Sebillo, M., Sol-Martinez, D., \& Vitiello, G. (2007b). Potentialities of Chorems as Visual Summaries of Geographic Databases Contents. In Advances in Visual Information Systems (pp. 537-548). Lecture Notes in Computer Science Vol. 4781, Berlin: Springer.

https://doi.org/10.1007/978-3-540-76414-4_52

Del Fatto, V., Laurini, R., Lopez, K., Sebillo, M., \& Vitiello, G. (2008). A Chorem-Based Approach for Visually Synthesizing Complex Phenomena, Information Visualization, 7, 253-264. https://doi.org/10.1057/PALGRAVE.IVS.9500186

Del Fatto, V., Laurini, R., Lopez, K., Sebillo, M., Tortora, G., Tucci, M., \& Vitiello, G. (2007a). Chorem Editing-Visual Summary of Spatial Database Content. In 13th International Conference on Distributed Multimedia Systems-Workshop on Visual Languages and Computing (pp. 256-259).

Dhieb, M. (1994). La cartographie de décision, outil d'aide à la décision. Géographie et Développement, No. 12, Tunis: Association des Géographes Tunisiens.

Dhieb, M. (2019). Translating Bertin into Arabic Today: New Hidden Facets of Semiology of Graphics. Cartography and Geographic Information Science, 46, 163-175. https://doi.org/10.1080/15230406.2018.1535332

Durand, M.-F., Levy, J., \& Retaille, D. (1992). Le Monde, Espaces et Systèmes (565 p.). Paris: Dalloz et les Presses de la Fondation nationale des sciences politiques.

Ferras, R. (1986). Atlas d'Espagne. Paris: Fayard-Reclus.

Klippel, A., Tappe, H., Kulik, L., \& Lee, P. U. (2005). Wayfinding Choremes: A Language for Modeling Conceptual Route Knowledge. Journal of Visual Languages and Computing, 16, 311-329. https://doi.org/10.1016/j.jvlc.2004.11.004 
Laurini, R., \& Serigne, S. (2001). Leçons tirées d'une expérience de chorémisation automatique. LIRIS-UMR 5205, Lyon: INSA de Lyon, Université de Lyon, 69621. https://perso.liris.cnrs.fr/rlaurini/text/Laurini-Servigne2.pdf

Laurini, R., Sebillo, M., Vitiello, G., Sol-Martinez, D., \& Raffort, F. (2009). Computer-Generated Visual Summaries of Spatial Databases: Chorems or Not Chorems? http://journals.openedition.org/sapiens/795

Lopez-Guillen, K. (2010). Résumés visuels des bases de données géographiques basés sur les chorèmes. Thèse de Doctorat Informatique, 23 juillet 2010. INSA de Lyon.

Lowy, P. (1985). Les médinas tunisiennes. Caen, Dépt. de Géogr. de l'Université, thèse inédite.

Martinuci, O. S. (2016). Geography, Graphical Semiology and Corematic. Mercator, 15, 37-52. http://www.mercator.ufc.br https://doi.org/10.4215/RM2016.1503.0003

Reimer, A. (2010). Understanding Chorematic Diagrams: Towards a Taxonomy. The Cartographic Journal, 47, 330-350.

https://doi.org/10.1179/000870410X12825500202896

Rodier, X., Grataloup, C., \& Guilloteau, C. (2015). Dossier: Chrono-chorématique urbaine. Revue Mappemonde, No. 117.

Théry, H. (1986). Atlas chorématique des régions du Brésil. Paris: Fayard-Reclus. 